\title{
Nonadherence and the Transition to Adulthood
}

\author{
Emily M. Fredericks \\ University of Michigan, Ann Arbor, Ml
}

Received June 18, 2009; accepted August 5, 2009.

\begin{abstract}
Key Points
1. Rates of nonadherence among pediatric transplant recipients are as high as $50 \%$ to $65 \%$, and this places adolescent transplant recipients at increased risk.

2. Adherence to immunosuppressant medications is a critical factor in the transition process as poor medication adherence is associated with an increased risk of poor long-term health outcomes.

3. Before transferring to adult-centered care, the pediatric transplant recipient should demonstrate adequate regimen knowledge and self-management skills.

4. Future research is needed to identify factors and interventions that affect long-term health outcomes in pediatric transplant recipients, including factors related to nonadherence and the successful transfer from pediatric care to adult-centered care. Liver Transpl 15:S63-S69, 2009. ๑ 2009 AASLD.
\end{abstract}

In 2007,605 children under the age of 18 years received liver transplants, accounting for approximately 9\% of all liver transplants in the United States. ${ }^{1}$ Among pediatric liver transplant recipients, patient survival rates are $90 \%$ at 1 year, $82 \%$ at 5 years, and $80 \%$ at 10 years post-transplantation. ${ }^{1,2}$ There have been significant improvements in the survival of pediatric liver transplant recipients, and they are reaching adulthood at increased rates. Although the number of new pediatric liver transplant recipients remains relatively stable each year, the population of long-term survivors following liver transplantation has grown. With increased short-term survival rates, health care providers have shifted their focus to long-term outcomes. Longterm patient survival is limited by chronic rejection and graft loss, which is more common in adolescents. ${ }^{3}$ Given the risk of medical complications following the transfer of care, there is a critical need to develop strat- egies to promote adherence and a successful transition from pediatric care to adult-centered health care. ${ }^{4-6}$

\section{MEDICATION NONADHERENCE IN PEDIATRIC TRANSPLANTATION}

The World Health Organization defines adherence as "the extent to which a person's behavior-taking medication, following a diet, and/or executing lifestyle changes, corresponds with agreed recommendations from a health care provider." 7 Regimen adherence is broader than taking immunosuppressive medications as it also encompasses other health behaviors, such as diet and exercise. However, research has primarily focused on the impact of nonadherence to immunosuppressant medications. ${ }^{8}$ Nonadherence to posttransplant medications is associated with significant consequences, including increased medical complications, graft rejection, posttransplant mortality, psychological distress, family dysfunction, and poor health-related quality of life..$^{9-12}$ Moreover, nonadherence in pediatric transplant recipients has the potential to negatively affect long-term health outcomes and quality of life, particularly during the transition from pediatric health care to adult-centered health care. ${ }^{4,5}$

Adolescent transplant recipients are at an increased risk for medication nonadherence. A recent review of the prevalence of nonadherence among adolescent transplant recipients revealed that nonadherence ranged from $17 \%$ to $53 \%$ among liver transplant recipients and from $5 \%$ to $71 \%$ among renal transplant recipients. ${ }^{13}$ The rate of medication nonadherence among adolescent transplant recipients is approximately 4 times higher than that among adult transplant recipients. ${ }^{14}$ These nonadherence rates are a concern as this is the population of patients that

Abbreviations: CCTC, certified clinical transplant coordinator; MEMS, Medication Event Monitoring System.

Address reprint requests to Emily M. Fredericks, Ph.D., University of Michigan, 1924 Taubman Center, SPC 5318, 1500 East Medical Center Drive, Ann Arbor, MI 48109-5318. Telephone: 734-615-3866; FAX: 734-936-6897; E-mail: emfred@med.umich.edu

DOI $10.1002 /$ lt.21892

Published online in Wiley InterScience (www.interscience.wiley.com). 
is closest to transferring their medical care to a new provider as they move from pediatric transplant services to adult-centered transplant services.

\section{ASSESSMENT OF MEDICATION ADHERENCE IN TRANSPLANTATION}

Although nonadherence to immunosuppressive medications has been estimated to be as high as 50\% to $65 \%,{ }^{13,15}$ the rates of nonadherence vary with the method of assessment and the definition of nonadherence. Within the adherence literature, it is common to define nonadherence as less than $80 \%$ to $85 \%$ compliance with medication taking. ${ }^{16}$ However, it is generally agreed that to increase the likelihood of favorable outcomes in transplantation, nearly perfect (ie, 100\%) adherence should be the goal, as minor deviations from a dosing schedule have been shown to be associated with negative outcomes. ${ }^{17,18}$ On the basis of a recent nonadherence consensus conference, nonadherence was defined as a "deviation from the prescribed medication regimen sufficient to influence adversely the regimen's intended effect." Yet, to date, studies of medication adherence in pediatric transplantation have been limited by a lack of an accepted gold-standard method for assessing adherence.

Medication adherence can be measured with various strategies. Patient/caregiver self-reports may be the least costly and feasible way to monitor adherence; however, self-reported adherence is often less accurate. $^{19}$ Electronic medication monitoring technology, such as the Medication Event Monitoring System (MEMS; Aprex Corp.), is considered a recommended measure in adherence research. ${ }^{20}$ MEMS technology provides continuous data and allows for the detection of temporal patterns of adherence. ${ }^{19}$ Yet, barriers associated with MEMS technology include its cost and the possibility that these devices may interfere with established adherence routines such as the use of pillbox organizers. ${ }^{21}$ Recent studies have attempted to measure adherence objectively by using the degree of fluctuation (ie, standard deviation) of medication blood levels of tacrolimus in pediatric liver transplant recipients. ${ }^{11,14,22,23}$ Higher standard deviations were predictive of clinical outcome, such as biopsy-proven rejection $^{14,22,23}$ and hospitalization rates. ${ }^{11}$ Variability in the blood levels of the immunosuppressant cyclosporine have also been associated with an increased risk of rejection in pediatric heart transplant recipients. ${ }^{24}$ Blood levels of cyclosporine (outside $150-400 \mathrm{ng} / \mathrm{mL}$ ) or tacrolimus (outside 5-17 ng/mL) outside the therapeutic range have also been shown to be indicators of poor adherence. $^{25}$

Each approach to measuring medication adherence has strengths and weaknesses, and this suggests a need for a multimethod assessment strategy. ${ }^{26}$ A recent study showed that a multimethod approach that included self-reports, drug assays, and clinician reports yielded the highest sensitivity (72\%) and specificity $(42 \%)$ in comparison with electronic monitoring alone. ${ }^{27}$ Future studies should focus on developing a standardized method for assessing medication adherence in transplant recipients.

\section{MEDICATION NONADHERENCE AND THE TRANSITION TO ADULT CARE}

The transition from pediatric health care to adult-centered health care is part of the developmental process for those with chronic childhood diseases and disabilities. In discussions of transition, there is often confusion between transition and transfer. The term transition refers to a complex set of beliefs, skills, and processes that facilitate the movement from pediatric care to adult-centered care, whereas the term transfer refers to the change in the location at which care is provided. ${ }^{28}$ Transition refers to the a multifaceted, active process that addresses the medical, psychosocial, and educational/vocational needs of adolescents as they prepare to move from child-centered health care to adult-centered health care. ${ }^{29}$ The transfer of care is only one outcome of the transition process and does not mark the end of the transition process, which should continue into adult-centered care. ${ }^{30}$

Medication adherence is considered a critical factor in the transition process because of an association between nonadherence and an increased risk of poor health outcomes, including increased graft loss and rejection, following the transfer from pediatric care to adult-centered care. ${ }^{4,5}$ A review of 20 patients who transferred from a pediatric renal transplant clinic to an adult renal transplant clinic revealed a high rate of unanticipated graft loss (35\%) within the first 3 years of transfer. ${ }^{5}$ For those with graft loss, the authors concluded that medication nonadherence was likely a contributing factor to the graft loss. In addition, a retrospective chart review of 14 pediatric transplant recipients who had transitioned to the adult service revealed that adherence to immunosuppressant medications significantly declined after the transfer of care, and medication adherence was significantly poorer in the newly transitioned cohort in comparison with pediatric and adult cohorts. ${ }^{4}$ Thus, the promotion of medication adherence behavior is a vital component of the transition process.

In a recent study, we conducted a retrospective analysis of pediatric liver transplant recipients who completed a clinically derived transition readiness screening measure used to assess regimen knowledge and self-management skills. ${ }^{31}$ Adherence was assessed with a multimethod approach incorporating standard deviations of consecutive blood levels of immunosuppressant medication, the proportion of immunosuppressant blood levels in the target therapeutic range, and the rate of clinic attendance. A composite adherence score was also constructed as an overall measure of adherence. Seventy-one pediatric liver transplant recipients were identified. The mean age of the participants was $15.6 \pm 2.7$ years, and the mean time since transplant was $9.4 \pm 5.4$ years. The results indicated that though the majority of adolescents correctly named their primary immunosuppressant medication, 
less than half could correctly state the prescribed dose/ timing or the basic function of their immunosuppressant. With respect to self-management skills, approximately half of the participants reported taking medications without parental prompting, though only $27 \%$ took their medications without parental supervision. The frequency of parental prompting for medication was significantly related to age, with older participants receiving less prompting. Rates of nonadherence ranged from $26 \%$ to $32 \%$. Poorer adherence was significantly related to older age and increased independence in medication taking. These results suggest that increased age is associated with decreased parental supervision and increased nonadherence. ${ }^{31}$

Research suggests an association between medication adherence, self-management skills, and health outcomes following the transfer from pediatric care to adult-centered care. Although medical regimen adherence may not be sufficient to lead to a successful transition process and transfer of care, it is necessary for optimal long-term health outcomes. ${ }^{32}$ Medication adherence behavior can be modified with intervention and should be targeted in transition preparation.

\section{DEVELOPMENTAL ISSUES IN SELF- MANAGEMENT AND TRANSITION}

The adolescent developmental period is characterized by changes in cognition, emotional attachments, physical development, independence, education/vocation, and self-identity. ${ }^{33}$ This stage of development is a critical period for the establishment of both positive and risky lifelong health-related behaviors. With respect to chronic illness, disease management, including medication adherence, is often at odds with typical adolescent development. ${ }^{34,35}$ The developmental characteristics associated with adolescence, including the development of autonomy from family, assimilation with peers, separation from parents, and poorly developed abstract thinking and understanding of long-term consequences of present actions, are often difficult to balance with the behaviors required for optimal medication adherence. ${ }^{36}$

In practice, chronological age is the most common criterion used to determine a patient's readiness to transfer from pediatric health care to adult-centered health care, with 16 to 22 years being the most frequently cited age range. ${ }^{37}$ Yet, consideration of selfmanagement skills is critical in determining a patient's progress toward independent health care management. A shared management model of transition describes a developmentally appropriate and systematic approach to the gradual shifting of self-management responsibilities from the healthcare provider and parent to the adolescent. ${ }^{38}$ When the responsibility for health-related tasks is shifted in a developmentally appropriate manner, the adolescent gains the knowledge, skills, and experiences necessary to master the independence required to be successful in the adult health care system.

\section{TABLE 1. Tasks to Achieve Prior to Transfer of Care}

1. Understanding of and the ability to describe the original cause of the organ failure and the subsequent need for transplantation

2. Awareness of the long-term and short-term implications of the transplant condition on overall health and other aspects of life

3. Knowledge related to medication, including the name, dose, function, timing, and side effects

4. Comprehension of the impact of the illness/transplant on reproductive health and sexuality

5. Demonstration of responsibility for one's own health care

6. Capacity to provide most self-care independently

7. Expressed readiness to move into adulthood

8. Ownership of medical information in a concise portable medical summary

9. Adequate insurance coverage

NOTE: This table was adapted from Bell et al. ${ }^{6}$

\section{DETERMINING READINESS TO TRANSFER CARE}

Researchers and clinicians agree that adolescents and young adults should not transfer from pediatric health services to adult health services unless they have the skills necessary for functioning effectively in the adult health care system. ${ }^{39,40}$ Recommendations for a successful transition include (1) a written health care plan, (2) the development of decision making and disease self-management, (3) attention to educational and vocational planning, (4) adequate insurance coverage, (5) transfer of health care to a qualified and committed adult specialist, and (6) involvement of the family in the transition process,. ${ }^{39,41,42}$ Generally, the key elements include the identification of a qualified and committed adult team, the development of a specific written health care transition plan, and the involvement of the family in the transition process. ${ }^{42-44}$ Goals of transition programs include the promotion of skills in communication, decision making, assertiveness, self-care, and self-advocacy. ${ }^{6}$

Specifically with respect to pediatric transplant recipients, a recent consensus conference sponsored by several transplant organizations to address issues related to the transition from pediatric care to adult-centered care identified critical milestones for adolescent and young adult patients to achieve prior to transferring care to the adult transplant clinic (Table 1$).{ }^{6}$ Overall, it is recommended that prior to transferring to adult-centered care, pediatric transplant recipients should be able to describe the reason for the transplant, be aware of how transplantation affects their overall health, and demonstrate a sense of responsibility and the capacity to independently manage their health. ${ }^{6}$ Moreover, it has been recommended that prior to physically transferring to the adult-centered clinic, pediatric transplant recipients should be able to describe their medication regimen, refill prescriptions independently, recognize how 
and when to seek medical attention, and be able to communicate with their health care providers. ${ }^{6}$

In adult care settings, patients are expected to demonstrate self-management skills, including the ability to independently discuss medical care with the treatment team, schedule and attend appointments, and adhere to medications and treatment recommendations. ${ }^{45}$ The successful transition from pediatric health care to adult-centered health care is contingent on the acquisition of self-management skills while patients are still being cared for by pediatric providers. As such, interventions should target modifiable factors related to the acquisition of the skills necessary for independent health care management.

\section{PREDICTORS OF SUCCESSFUL TRANSITION}

Research is needed to define and identify predictors of a successful transition in order to inform the development of programs that target modifiable factors. ${ }^{46}$ Initial studies have focused on medical stability ${ }^{4,47}$ and the initial attendance at a clinic appointment in the adult health care center ${ }^{48}$ as markers of a successful transition. It is important to underscore that transition is a preparation process that occurs prior to and after the shift in care. A primary outcome variable of the transition process includes the transfer to adult-centered care (eg, a change of care provider and/or location). However, there is no evidence to suggest that the mere transfer of care is sufficient to promote long-term positive health behaviors or outcomes. In addition to clinic attendance, future research should assess the impact of the health care transition on measures of patient satisfaction, medical stability, quality of life, psychosocial functioning, educational/vocational outcomes, and health care utilization rates.

\section{POTENTIAL RISKS AND BARRIERS ASSOCIATED WITH MEDICATION ADHERENCE AND TRANSITION}

The limited data available (Scientific Registry of Transplant Recipients/Organ Procurement and Transplantation Network data) suggest that the transfer to adultcentered care does not increase graft loss; rather, the increase in graft loss in adolescents begins in early adolescence and continues into young adulthood. ${ }^{49}$ Medical regimen adherence has been suggested to be a critical factor in the transition process because of an association between nonadherence and an increased risk of poor outcomes, including higher rates of graft loss, following the transfer from pediatric care to adult-

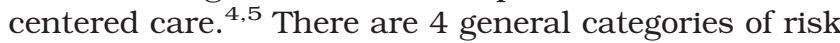
factors associated with medication adherence, including socioeconomic factors, patient-related factors, condition-related and/or treatment-related factors, and environmental variables. ${ }^{7}$ Within the transplant literature, medication nonadherence has been demonstrated to be associated with inadequate regimen knowledge, depression and anxiety, poor health-related quality of life, low social support, substance abuse, life stress, barriers to medication access, and a poor physicianpatient relationship. ${ }^{11,12,50-52}$ In addition, among adolescent transplant recipients, medication nonadherence has been associated with increased disease frustration, poor regimen adaptation/cognitive issues, difficulty with ingestion (eg, number of medications and taste), and a lack of parental involvement. ${ }^{53}$ Targeting barriers to medication adherence is a critical component to transition planning.

In addition to medication nonadherence, there are additional barriers to the transition of health care, including patient-related factors, parent/caregiver factors, medical team factors, and systemic factors. Examples of barriers include the reluctance of patients, parents, and pediatric physicians to transfer care (ie, not "letting go"), ${ }^{43,54,55}$ a lack of trust between pediatric and adult-care health providers, ${ }^{29,56}$ financial disincentives for transferring patients out of the pediatric clinics, ${ }^{56}$ and adolescent psychosocial functioning and medication nonadherence. ${ }^{39,57}$ Further research is necessary to identify optimal strategies to prevent and reconcile these barriers and risk factors.

\section{INTERVENTIONS TO PROMOTE ADHERENCE AND SELF-MANAGEMENT SKILLS}

There are no empirically validated interventions to promote medication adherence or transition readiness in pediatric transplant recipients. Given that adolescent transplant recipients are at the highest risk for nonadherence $^{14}$ and late graft loss associated with medication nonadherence, ${ }^{3}$ interventions aimed at improving medication adherence in adolescent transplant recipients are critical. Self-management has been effective in improving medication adherence in children with other chronic health conditions. ${ }^{58,59}$ Key elements of selfmanagement include the promotion of health education, communication skills, decision-making and problem-solving skills, and self-care in the context of meaningful social support. ${ }^{60}$ Self-management skills are integral to both optimal medication adherence and the achievement of independence necessary for a successful health care transition. ${ }^{61,62}$

\section{TRANSITION PROGRAMS IN OTHER PEDIATRIC POPULATIONS}

Transition programs in other pediatric populations, such as rheumatology, ${ }^{63}$ cystic fibrosis, ${ }^{64}$ and inflammatory bowel disease, ${ }^{65}$ can provide guidance for the development of transition programs in pediatric solid organ transplantation. For example, key components of a transitional care program for adolescents with juvenile idiopathic arthritis include a resilience framework to focus on the development of health-related information and behavioral skills, ${ }^{63}$ including decision-making, self-care, and self-management skills. The benefits of transition programs in rheumatology include improved quality of life, knowledge, health care satisfaction, and vocational readiness. ${ }^{66}$ Existing transition programs emphasize the use of transition timelines, 
which are constructed according to a developmental framework that considers chronological age as well as the developmental stage of the patient. These timelines are individualized and emphasize the acquisition of critical milestones, with respect to knowledge and selfmanagement skills, prior to the transfer of medical care from a pediatric-focused clinic to an adult-focused clinic. Sample transition timelines and checklists can be found on the Children's Digestive Health and Nutrition Foundation Web site (http://www.cdhnf.org) and on the Adolescent Health Transition Project Web site (http://depts.washington.edu/healthtr).

Research suggests that transition preparation should begin years prior to the anticipated change of medical care providers. ${ }^{63-65}$ Yet, in order for transition preparation to lead to optimal long-term outcomes, it is necessary to have an interested adult health care team to provide care after transfer. Collaboration between pediatric and adult transplant teams is essential, particularly as evidence in other pediatric groups (eg, cystic fibrosis) demonstrates that health outcomes are not compromised when the transfer of care is a cooperative, planned process between pediatric and adult care providers. ${ }^{67}$

\section{ROLE OF CERTIFIED CLINICAL TRANSPLANT COORDINATORS (CCTCs)}

The Pediatric Committee of the American Society of Transplantation has recommended that adolescent transplant recipients have a designated health care transition coordinator ${ }^{6}$ to facilitate the transition process. Indeed, an identified transitional care coordinator is a core component of transitional care as outlined in national policy statements. ${ }^{42,68}$ Nurse practitioners are most likely to serve as transition coordinators ${ }^{69}$; however, CCTCs are also in a position to take a leadership role in transitional care programming. Specifically, CCTCs can (1) educate patients and families about the importance of transition readiness and the necessary skills to promote a successful transfer of care, (2) facilitate communication regarding transition milestones and readiness to transfer care, and (3) anticipate barriers related to the transfer from pediatric care to adultcentered care.

In collaboration with other medical team members, CCTCs can assist adolescent transplant recipients in working toward the achievement of critical tasks and milestones (Tables 1 and 2). As key transition coordinators, CCTCs can assist with the development of a written health care transition plan that sets forth a timeline for the achievement of self-management skills to promote independence in health care management. Transition coordinators can also assist with preparing parents by educating them on strategies to increase the adolescent's responsibility for health care tasks in a developmentally appropriate manner.

Not only can CCTCs assist families with the transition process, but they also can serve as liaisons at the time of transfer by facilitating the transfer of health care information in a portable, concise, up-to-date summary
TABLE 2. Transition Planning Tasks: The Role of a Clinical Transplant Coordinator

- Develop an individualized written health care transition plan for each patient and his or her family.

- Develop a checklist of developmentally appropriate selfmanagement tasks and milestones to achieve prior to transfer of care.

- Monitor progress using the checklist and the written transition plan at each clinic visit, and set goals for subsequent visits.

- Prepare and support parents in the transition process by providing education on developmentally appropriate tasks and goals for increasing the adolescent's responsibility for health care management.

- Encourage educational and vocational planning throughout childhood and adolescence.

- Provide guidance and needed referrals to patients and their families with respect to medical insurance coverage prior to transfer of care.

- Collaborate with medical care providers to develop a portable, up-to-date, concise medical summary for each patient, and ensure that patients and their families have copies of this summary.

- Facilitate communication between pediatric and adult care providers prior to the transfer of care.

- Facilitate communication between each patient, his or her family, and adult care providers with respect to the logistics of the transfer of care (ie, clinic procedures, location, and scheduling).

of the adolescent's medical/surgical history and medications. ${ }^{6}$ Although the successful transition from pediatric health care to adult-centered health care is likely contingent on the acquisition of self-management skills while patients are still being cared for by pediatric providers, collaboration with interested adult transplant care providers is critical to ensure optimal health care transitions and long-term outcomes. ${ }^{70}$ Effective communication between pediatric and adult services is imperative, and CCTCs on the adult transplant team can assist with the transition process by collaborating with pediatric transplant coordinators to facilitate the transfer of care, including the transfer of relevant medical information.

\section{CONCLUSIONS}

Nonadherence to posttransplant medical regimens is associated with increased medical complications, graft rejection, mortality, and health care utilization rates. Adolescent solid organ transplant recipients are at a higher risk for regimen nonadherence than younger pediatric patients and adult recipients. Given that nonadherence is associated with an increased risk for medical complications, particularly among adolescent transplant recipients, targeting problems of nonadherence should be an essential component of the transition process. Prospective research to validate a measure to identify factors predictive of a successful transfer of care and successful health outcomes is needed. Transition preparation is a continuous process and should 
incorporate interventions to promote self-management skills and adherence as pediatric patients prepare to move from child-centered care to adult-centered care. CCTCs are well suited to serve as transition coordinators to facilitate education, communication, and collaboration between patients, families, pediatric transplant teams, and adult transplant teams.

\section{REFERENCES}

1. Organ Procurement and Transplantation Network/Scientific Registry of Transplant Recipients. 2007 Annual Report of the U.S. Organ Procurement and Transplantation Network and the Scientific Registry of Transplant Recipients: Transplant Data 1997-2006. Rockville, MD: Health Resources and Services Administration; 2007.

2. Berg CL, Steffick DE, Edwards EB, Heimbach JK, Magee JC, Washburn WK, et al. Liver and intestine transplantation in the United States 1998-2007. Am J Transplant 2009;9(pt 2):907-931.

3. Sudan DL, Shaw BW Jr, Langnas AN. Causes of late mortality in pediatric liver transplant recipients. Ann Surg 1998;227:289-295.

4. Annunziato RA, Emre S, Shneider B, Barton C, Dugan CA, Shemesh E. Adherence and medical outcomes in pediatric liver transplant recipients who transition to adult services. Pediatr Transplant 2007;11:608-614.

5. Watson AR. Non-compliance and transfer from paediatric to adult transplant unit. Pediatr Nephrol 2000;14:469472.

6. Bell LE, Bartosh SM, Davis CL, Dobbels F, Al-Uzri A, Lotstein D, et al. Adolescent transition to adult care in solid organ transplantation: a consensus conference report. Am J Transplant 2008;8:2230-2242.

7. Sabate E. Adherence to Long-Term Therapies: Evidence for Action. Geneva, Switzerland: World Health Organization; 2003.

8. Fine RN, Becker Y, De Geest S, Eisen H, Ettenger R, Evans $\mathrm{R}$, et al. Nonadherence consensus conference summary report. Am J Transplant 2009;9:35-41.

9. Butler JA, Roderick P, Mullee M, Mason JC, Peveler RC. Frequency and impact of nonadherence to immunosuppressants after renal transplantation: a systematic review. Transplantation 2004;77:769-776.

10. Griffin KJ, Elkin TD. Non-adherence in pediatric transplantation: a review of the existing literature. Pediatr Transplant 2001;5:246-249.

11. Fredericks EM, Lopez MJ, Magee JC, Shieck V, OpipariArrigan L. Psychological functioning, nonadherence and health outcomes after pediatric liver transplantation. Am J Transplant 2007;7:1974-1983.

12. Fredericks EM, Magee JC, Opipari-Arrigan L, Shieck V, Well A, Lopez MJ. Adherence and health-related quality of life in adolescent liver transplant recipients. Pediatr Transplant 2008;12:289-299.

13. Dobbels F, Van Damme-Lombaert R, Vanhaecke J, De Geest S. Growing pains: non-adherence with the immunosuppressive regimen in adolescent transplant recipients. Pediatr Transplant 2005;9:381-390.

14. Shemesh E, Shneider BL, Savitzky JK, Arnott L, Gondolesi GE, Krieger NR, et al. Medication adherence in pediatric and adolescent liver transplant recipients. Pediatrics 2004; 113:825-832.

15. Wainwright SP, Gould D. Non-adherence with medications in organ transplant patients: a literature review. J Adv Nurs 1997;26:968-977.

16. Rapoff MA. Adherence to Pediatric Medical Regimens. New York, NY: Kluwer Academic/Plenum Press; 1999.
17. Nevins TE, Kruse L, Skeans MA, Thomas W. The natural history of azathioprine compliance after renal transplantation. Kidney Int 2001;60:1565-1570.

18. De Geest S, Abraham I, Moons P, Vandeputte M, Van Cleemput J, Evers G, et al. Late acute rejection and subclinical noncompliance with cyclosporine therapy in heart transplant recipients. J Heart Lung Transplant 1998;17: 854-863.

19. Farmer KC. Methods for measuring and monitoring medication regimen adherence in clinical trials and clinical practice. Clin Ther 1999;21:1074-1090; discussion 3.

20. Butler JA, Peveler RC, Roderick P, Horne R, Mason JC. Measuring compliance with drug regimens after renal transplantation: comparison of self-report and clinician rating with electronic monitoring. Transplantation 2004; 77:786-789.

21. Shellmer DA, Zelikovsky N. The challenges of using medication event monitoring technology with pediatric transplant patients. Pediatr Transplant 2007;11:422-428.

22. Bucuvalas JC, Ryckman FC, Arya G, Andrew B, Lesko A, Cole $\mathrm{CR}$, et al. A novel approach to managing variation: outpatient therapeutic monitoring of calcineurin inhibitor blood levels in liver transplant recipients. J Pediatr 2005; 146:744.

23. Stuber ML, Shemesh E, Seacord D, Washington J, Hellemann G, McDiarmid S. Evaluating non-adherence to immunosuppressant medications in pediatric liver transplant recipients. Pediatr Transplant 2008;12:284-288.

24. Flippin MS, Canter CE, Balzer DT. Increased morbidity and high variability of cyclosporine levels in pediatric heart transplant recipients. J Heart Lung Transplant 2000; 19:343-349.

25. Chisholm MA, Lance CE, Williamson GM, Mulloy LL. Development and validation of an immunosuppressant therapy adherence barrier instrument. Nephrol Dial Transplant 2005;20:181-188.

26. Quittner AL, Modi AC, Lemanek KL, Ievers-Landis CE, Rapoff MA. Evidence-based assessment of adherence to medical treatments in pediatric psychology. J Pediatr Psychol 2008;33:916-936.

27. Schafer-Keller P, Steiger J, Bock A, Denhaerynck K, De Geest S. Diagnostic accuracy of measurement methods to assess non-adherence to immunosuppressive drugs in kidney transplant recipients. Am J Transplant 2008;8:616626.

28. Sawyer SM, Blair S, Bowes G. Chronic illness in adolescents: transfer or transition to adult services? J Paediatr Child Health 1997;33:88-90.

29. Blum RW, Garell D, Hodgman CH, Jorissen TW, Okinow NA, Orr DP, et al. Transition from child-centered to adult health-care systems for adolescents with chronic conditions. A position paper of the Society for Adolescent Medicine. J Adolesc Health 1993;14:570-576.

30. Kennedy A, Sawyer S. Transition from pediatric to adult services: are we getting it right? Curr Opin Pediatr 2008; 20:403-409.

31. Fredericks EM, Dore-Stites D, Well A, Shieck V, Magee JC, Lopez MJ. Transition readiness and adherence among pediatric liver transplant recipients [abstract]. Am J Transplant 2009;9(suppl 2):109.

32. Bucuvalas J, Alonso E, Magee J, Talwalkar J, Hanto D, Doo E. Improving long-term outcomes after liver transplantation in children. Am J Transplant 2008;8:1-8.

33. Kaufman M. Role of adolescent development in the transition process. Prog Transplant 2006; 16:286-290.

34. Shaw RJ. Treatment adherence in adolescents: development and psychopathology. Clin Child Psychol Psychiatry 2001;6:137-150.

35. La Greca AM, Bearman KJ. Adherence to pediatric treat- 
ment regimens. In: Roberts MC, ed. Handbook of Pediatric Psychology. New York, NY: Guilford Press; 2003:1 19-140.

36. Suris JC, Michaud PA, Viner R. The adolescent with a chronic condition. Part I: developmental issues. Arch Dis Child 2004;89:938-942.

37. Betz CL. Transition of adolescents with special health care needs: review and analysis of the literature. Issues Compr Pediatr Nurs 2004;27:179-241.

38. Gall C, Kingsnorth S, Healy H. Growing up ready: a shared management approach. Phys Occup Ther Pediatr 2006; 26:47-62.

39. McDonagh JE. Growing up and moving on: transition from pediatric to adult care. Pediatr Transplant 2005;9: 364-372.

40. Viner R. Transition from paediatric to adult care. Bridging the gaps or passing the buck? Arch Dis Child 1999;81: 271-275.

41. Scal P, Evans T, Blozis S, Okinow N, Blum R. Trends in transition from pediatric to adult health care services for young adults with chronic conditions. J Adolesc Health 1999;24:259-264

42. American Academy of Pediatrics, American Academy of Family Physicians, American College of Physicians. A consensus statement on health care transitions for young adults with special health care needs. Pediatrics 2002; 110:1304-1306.

43. Viner R. Barriers and good practice in transition from paediatric to adult care. J R Soc Med 2001;94(suppl 40): 2-4.

44. Bucuvalas JC, Alonso E, Magee JC, Talwalkar J, Hanto D, Doo E. Improving long-term outcomes after liver transplantation in children. Am J Transplant 2008;8:25062513.

45. Kennedy A, Sloman F, Douglass JA, Sawyer SM. Young people with chronic illness: the approach to transition. Intern Med J 2007;37:555-560.

46. Freed GL, Hudson EJ. Transitioning children with chronic diseases to adult care: current knowledge, practices, and directions. J Pediatr 2006; 148:824-827.

47. Nasr SZ, Campbell C, Howatt W. Transition program from pediatric to adult care for cystic fibrosis patients. J Adolesc Health 1992;13:682-685.

48. Reid GJ, Irvine MJ, McCrindle BW, Sananes R, Ritvo PG, Siu SC, et al. Prevalence and correlates of successful transfer from pediatric to adult health care among a cohort of young adults with complex congenital heart defects. Pediatrics 2004;113:e197-e205.

49. Magee JC, Thomas SE, Fredericks EM, Guidinger MK, Port FK, Kalbfleisch JD, et al. Effect of recipient age and "transition" on graft loss in pediatric transplant recipients [abstract]. Am J Transplant 2006;6(suppl 2):65.

50. Dew MA, Roth LH, Thompson ME, Kormos RL, Griffith BP. Medical compliance and its predictors in the first year after heart transplantation. J Heart Lung Transplant 1996; 15:631-645.

51. Bunzel B, Laederach-Hofmann K. Solid organ transplantation: are there predictors for posttransplant noncompliance? A literature overview. Transplantation 2000;70:711-716.

52. Shapiro PA, Williams DL, Foray AT, Gelman IS, Wukich N, Sciacca R. Psychosocial evaluation and prediction of compliance problems and morbidity after heart transplantation. Transplantation 1995;60:1462-1466.
53. Simons LE, Blount RL. Identifying barriers to medication adherence in adolescent transplant recipients. J Pediatr Psychol 2007;32:831-844.

54. Landau LI. Cystic fibrosis: transition from paediatric to adult physician's care. Thorax 1995;50:1031-1032.

55. Rosen D. Between two worlds: bridging the cultures of child health and adult medicine. J Adolesc Health 1995; 17:10-16.

56. Schidlow DV, Fiel SB. Life beyond pediatrics. Transition of chronically ill adolescents from pediatric to adult health care systems. Med Clin North Am 1990;74:1113-1120.

57. McDonagh JE, Kelly DA. Transitioning care of the pediatric recipient to adult caregivers. Pediatr Clin North Am 2003;50:1561-1583.

58. Creer TL. Self-management and the control of chronic pediatric illness. In: Drotar D, ed. Promoting Adherence to Medical Treatment in Chronic Childhood Illness: Concepts, Methods and Interventions. Hillsdale, NJ: Erlbaum; 2000:95-129.

59. Lemanek KL, Kamps J, Chung NB. Empirically supported treatments in pediatric psychology: regimen adherence. J Pediatr Psychol 2001;26:253-275.

60. Sawyer SM, Aroni RA. Self-management in adolescents with chronic illness. What does it mean and how can it be achieved? Med J Aust 2005; 183:405-409.

61. Watson AR. Problems and pitfalls of transition from paediatric to adult renal care. Pediatr Nephrol 2005;20:113.

62. McDonagh JE, Hackett J. Interrelationship of self-management and transitional care needs of adolescents with arthritis: comment on the article by Stinson et al. Arthritis Rheum 2008;59:1199-1200; author reply 1200-1201.

63. McDonagh JE. Young people first, juvenile idiopathic arthritis second: transitional care in rheumatology. Arthritis Rheum 2008;59:1162-1170.

64. McLaughlin SE, Diener-West M, Indurkhya A, Rubin H, Heckmann R, Boyle MP. Improving transition from pediatric to adult cystic fibrosis care: lessons from a national survey of current practices. Pediatrics 2008;121:e1160el166.

65. Hait E, Arnold JH, Fishman LN. Educate, communicate, anticipate-practical recommendations for transitioning adolescents with IBD to adult health care. Inflamm Bowel Dis 2006; 12:70-73.

66. McDonagh JE, Southwood TR, Shaw KL. The impact of a coordinated transitional care programme on adolescents with juvenile idiopathic arthritis. Rheumatology (Oxford) 2007;46:161-168.

67. Duguépéroux I, Tamalet A, Sermet-Gaudelus I, Le Bourgeois M, Gérardin M, Desmazes-Dufeu N, et al. Clinical changes of patients with cystic fibrosis during transition from pediatric to adult care. J Adolesc Health 2008;43: 459-465.

68. Rosen DS, Blum RW, Britto M, Sawyer SM, Siegel DM. Transition to adult health care for adolescents and young adults with chronic conditions: position paper of the Society for Adolescent Medicine. J Adolesc Health 2003;33: 309-311.

69. Betz CL, Redcay G. Dimensions of the transition service coordinator role. J Spec Pediatr Nurs 2005;10:49-59.

70. McDonagh JE, Kelly DA. Adolescence and transition to adult care. In: Kelly DA, ed. Diseases of the Liver and Biliary System in Children. Hoboken, NJ: Wiley-Blackwell; 2008:599-613. 